\title{
Organisational justice and health of employees: prospective cohort study
}

\author{
M Kivimäki, M Elovainio, J Vahtera, J E Ferrie
}

Occup Environ Med 2003;60:27-34

\begin{abstract}
Aims: To examine the association between components of organisational justice (that is, justice of decision making procedures and interpersonal treatment) and health of employees.

Methods: The Poisson regression analyses of recorded all-cause sickness absences with medical certificate and the logistic regression analyses of minor psychiatric morbidity, as assessed by the General Health Questionnaire, and poor self rated health status were based on a cohort of 416 male and 3357 female employees working during 1998-2000 in 10 hospitals in Finland. Results: Low versus high justice of decision making procedures was associated with a $41 \%$ higher risk of sickness absence in men (rate ratio (RR) 1.4, 95\% confidence interval (CI) 1.1 to 1.8), and a $12 \%$ higher risk in women (RR $1.1,95 \% \mathrm{Cl} 1.0$ to 1.2 ) after adjustment for baseline characteristics. The corresponding odds ratios (OR) for minor psychiatric morbidity were $1.6(95 \% \mathrm{Cl} 1.0$ to 2.6$)$ in men and $1.4(95 \% \mathrm{Cl} 1.2$ to 1.7$)$ in women, and for self rated health 1.4 in both sexes. In interpersonal treatment, low justice increased the risk of sickness absence (RR $1.3(95 \% \mathrm{Cl} 1.0$ to 1.6$)$ and RR $1.2195 \%$ $\mathrm{Cl} 1.2$ to 1.3 ) in men and women respectively), and minor psychiatric morbidity (OR 1.2 in both sexes). These figures largely persisted after control for other risk factors (for example, job control, workload, social support, and hostility) and they were replicated in initially healthy subcohorts. No evidence was found to support the hy:
health (reversed causality).

Conclusions: This is the first longitudinal study to show that the extent to which people are treated with justice in workplaces independently predicts their health.
\end{abstract}

See end of article for authors' affiliations

Correspondence to: Prof. M Kivimäki,

Department of Psychology, Division of Applied Psychology, University of Helsinki, PO Box 13, FIN-00014, Finland; mika.kivimäki@occuphealth.fi

Accepted

13 February 2002

$\mathrm{T}$ he importance of work for health goes beyond traditional diseases caused by physical and chemical hazards. Research suggests that psychosocial characteristics of the work environment such as job control, work load, and social support affect health of employees. ${ }^{1-5}$ However, other psychosocial work characteristics may also play a role in employee health.

The pursuit of justice is assumed to be a fundamental aspect of any social organisation, including workplaces. ${ }^{6}$ The term "organisational justice" refers to the extent to which employees are treated with justice at their workplace. ${ }^{7}$ Organisational justice involves a procedural component and a relational component. The former indicates whether decision making procedures include input from affected parties, are consistently applied, suppress bias, are accurate, are correctable, and are ethical. The latter element refers to the polite and considerate treatment of individuals by supervisors. Although the associations of organisational justice with work motivation, job satisfaction, and work commitment have been shown, ${ }^{7}$ little is known about the potential impact of organisational justice on employee health.

Previous research suggests that low organisational justice and unfair treatment are related to factors that influence susceptibility to illness, such as raised unfavourable serum lipids and negative feelings. ${ }^{89}$ Our own recent work using cross sectional data from a study of Finnish hospital personnel has shown low procedural justice to be associated with increased risk of sickness absence, minor psychiatric morbidity, and poor self rated health in men and women. ${ }^{10}$ Relational justice was also associated with these outcomes with the exception that in men the association with self rated health was nonsignificant.

A limitation in the existing evidence is its reliance on cross sectional data. Such data cannot rule out the alternative possibility that health problems may increase the likelihood of being treated unfairly, or feelings of unjustice, or both. In these cases, organisational justice would represent a consequence of health rather than a predictor of health (reverse causality hypothesis). Confounding factors may also underlie the association: one may suspect that organisational justice is only a marker for other psychosocial factors that influence health (for example, job control, workload, social support, and hostility) and uncertainty remains whether organisational justice predicts health independently of behavioural and biological risk factors.

In the present study we expand our previous work among Finnish hospital personnel, ${ }^{10}$ using longitudinal data and an increased sample size to investigate the association between organisational justice and the health of employees. The longitudinal nature of the present study allows us to address the issue of reverse causality. Data on psychosocial characteristics of the work environment, and behavioural, and biological markers allow us to explore whether organisational justice independently predicts health.

\section{METHODS}

\section{Study sample}

This study is a part of an ongoing project "Work and health in Finnish hospital personnel" coordinated by the Finnish Institute of Occupational Health. In a survey carried out between January and April 1998, all 7375 employees (1156 men, 6219 women) in the service of the 10 hospitals in two of the 23 health care districts in Finland were asked to respond to a questionnaire on organisational justice, minor psychiatric morbidity, health status, and other variables. Of the sample,

Abbreviations: $\mathrm{Cl}$, confidence interval; $\mathrm{OR}$, odds ratio; $\mathrm{RR}$, rate ratio 
$10 \%$ were doctors ( 434 men and 312 women), $46 \%$ nurses (233 men and 3155 women), 14\% $x$ ray and laboratory staff (56 men and 963 women), 12\% administrative staff ( 97 men and 766 women), and $18 \%$ maintenance, cleaning, and other staff (336 men and 1023 women). Data on sickness absence were obtained from employers' registers for 1997 to 1999, and a follow up survey was conducted early in 2000.

\section{Measurements}

\section{Procedural justice}

The scale ${ }^{10}{ }^{11}$ (range 1-5, Cronbach's $\alpha=0.80$ ) was based on the degree to which the respondent agreed with the following statements concerning the procedures used at the workplace:

(1) Procedures are designed to hear the concerns of all those affected by the decision.

(2) Procedures are designed to collect accurate information necessary for making decisions.

(3) Procedures are designed to provide opportunities to appeal or challenge the decision.

(4) Procedures are designed to generate standards so that decisions can be made with consistency.

Relational justice

The scale ${ }^{10}{ }^{11}$ (range $1-5, \alpha=0.90$ ) was based on the following statements about the general behaviour of the respondent's supervisor:

(1) Your supervisor considers your viewpoint.

(2) Your supervisor is able to suppress personal biases.

(3) Your supervisor treats you with kindness and consideration.

(4) Your supervisor takes steps to deal with you in a truthful manner.

In both organisational justice scales, responses were given along a five point scale from $5=$ strongly agree to $1=$ strongly disagree.

\section{Health indicators}

The outcome variables were: recorded medically certified sickness absence, minor psychiatric morbidity, and self rated health status. The number of medically certified sickness absence spells over seven days between 1 January and 31 December 1997 represented baseline absence rate, and that between 1 January 1998 and 31 December 1999 the outcome. Employers' registers documented each period of sick leave for every employee, giving the beginning and end dates of each spell. Maternity leave and absence as a result of caring for a sick child were not included in sickness absences. Minor psychiatric morbidity was assessed using the 12 item version of the General Health Questionnaire (GHQ-12). Individuals scoring 4 or more are estimated to have minor psychiatric morbidity according to studies validating GHQ-12 against standardised psychiatric interviews, ${ }^{12}$ and this threshold was applied in the present study. Poor health status was indicated by health ratings less than good on a five point scale.

\section{Other measurements}

Covariates were measured in standard ways: age, sex, income, smoking status (current smoker versus not), alcohol consumption (high consumption $>280 \mathrm{~g}$ and $>190 \mathrm{~g}$ of absolute alcohol per average week for men and women, respectively), ${ }^{13}$ sedentary lifestyle (less than half an hour of fast walking per week), ${ }^{14}$ and obesity (BMI $\left.>30 \mathrm{~kg} / \mathrm{m}^{2}\right)$. Scales assessing psychosocial factors were decision authority (three items, range $1-5, \alpha=0.81$ ) and skill discretion (six items, range $1-5$, $\alpha=0.81$ ), ${ }^{15}$ as dimensions of job control, workload (five items, range $1-5, \alpha=0.83$ ), ${ }^{10}$ social support ( six items, range $0-30$, $\alpha=0.82$ ), ${ }^{16}$ and hostility (three items, range $1-7, \alpha=0.62$ ). ${ }^{17}$
These scales have successfully predicted health in prior prospective cohort studies. $^{217-20}$

\section{Ethical approval}

Ethical approval for the project "Work and health in Finnish hospital personnel" was obtained from the ethics committee of the Finnish Institute of Occupational Health.

\section{Statistical analysis}

We used the SAS program package for all analyses. Mean levels of dimensions of organisational justice at baseline and at follow up were calculated, and differences between sexes, age and income groups, those who were initially healthy and those who had health problems at baseline, were tested by repeated measures analysis of variance. In this analysis, age and income were divided into high and low using median split separately for men and women. To test the reverse causality hypothesis, the difference in changes of organisational justice between the initially healthy and those with health problems at baseline was tested. A significant interaction term between time and baseline health would support the reverse causality hypothesis if the change in justice proved to be more adverse among those with health problems.

We checked records of sickness absence and job contracts for inconsistencies and combined any overlapping or consecutive periods of sickness absence. The number of periods of sick leave and the follow up period in person years were calculated for each employee. Because the number of sick leaves is in the form of frequency data, Poisson regression models were fitted. ${ }^{1921}$ Use of the Poisson model implies that the between employee variance in the rates of sick leave is equal to the expected rate of sick leave. In this study, the dispersion in rates of sick leave did not significantly differ from that predicted from the Poisson model. We identified cases of minor psychiatric morbidity and poor self rated health status and used logistic regression models in relation to these data.

We used regression models to estimate the strength of the relations between organisational justice and indicators of health among men and women. Components of organisational justice were standardised and treated as continuous variables. The rate ratios for sick leaves and odds ratios for minor psychiatric morbidity and poor self rated health status for components of organisational justice at high and low levels were calculated. The cut off points for high and low organisational justice were set at +1 standard deviation (SD) and -1 $\mathrm{SD}$, respectively. We adjusted rate ratios and odds ratios and their 95\% confidence intervals for demographics (age and income) and health indicators at baseline. Interactions with sex, income, and age were tested using a cross product term. Analyses were conducted for all participants and for the initially healthy subcohort-that is, those with no sickness absence in the baseline, GHQ-12 score below 4, and self rated health either good or very good.

The role of other factors in the association between organisational justice and health was studied. We examined the degree to which organisational justice components were related to behavioural and biological factors (smoking, alcohol consumption, sedentary lifestyle, and obesity) by logistic regression analysis and the degree they were related to other psychosocial factors (that is, components of job control, work load, social support, and hostility) by calculating a Pearson product moment correlation matrix for these variables.

In regression models explaining health outcomes, the effects of organisational justice and other psychosocial factors were adjusted for behavioural and biological variables in addition to demographics and baseline health. All psychosocial factors were treated as continuous variables and standardised, with cut off points for high and low levels set to +1 SD and -1 $\mathrm{SD}$, respectively. Biological and behavioural variables were dichotomous. 
Table 1 Sample attrition by occupational groups

\begin{tabular}{lllllr}
\hline & \multicolumn{2}{l}{ 1st survey } & & \multicolumn{2}{l}{ 2nd survey } \\
\cline { 2 - 3 } \cline { 5 - 6 } Occupational group & $\begin{array}{l}\text { Eligible population } \\
\mathrm{n}(\%)\end{array}$ & $\begin{array}{l}\text { Respondents } \\
\mathrm{n}(\%)\end{array}$ & & $\begin{array}{l}\text { Eligible population } \\
\mathrm{n}(\%)\end{array}$ & $\begin{array}{l}\text { Respondents } \\
\mathrm{n}(\%)\end{array}$ \\
\hline Physicians & $746(10)$ & $399(7)$ & & $290(6)$ & $216(6)$ \\
Nurses & $3388(46)$ & $2822(50)$ & & $2383(51)$ & $2013(53)$ \\
$x$ Ray and laboratory staff & $1019(14)$ & $764(13)$ & & $628(13)$ & $470(12)$ \\
Administrative staff & $863(12)$ & $666(12)$ & & $561(12)$ & $446(12)$ \\
Maintenance, cleaning, & $1359(18)$ & $1017(18)$ & & $832(18)$ & $628(17)$ \\
and other staff & $7375(100)$ & $5668(100)$ & & $4694(100)$ & $3773(100)$ \\
Total & & &
\end{tabular}

Finally, we examined the independent contributions of organisational justice components and other psychosocial predictors in fully adjusted models in which the effect of each variable was adjusted for demographics, baseline health, behavioural and biological variables, and those psychosocial factors that separately predicted each health outcome.

\section{RESULTS}

\section{Response rates and attrition}

Altogether 5668 (77\%) employees (679 men, 4989 women) responded to the baseline questionnaire. Respondents did not differ from the eligible population in terms of age (43.4 $v 43.7$ years) and annual income (131 $183 v 134836$ FIM), but female employees were slightly over represented ( $88 \% v 84 \%)$. The proportion of physicians was 3\% and the proportion of nurses $4 \%$ higher in respondents than in the eligible employees. Differences in proportions of other occupational groups between respondents and eligible population were less than $1 \%$ (table 1).

Of the respondents to the baseline questionnaire, $974 \mathrm{had}$ lost or left their jobs with the hospitals before the follow-up survey. These participants had a higher rate of sickness

Table 2 Means of organisational justice at baseline and at follow up by baseline characteristics; repeated measures analysis of variance for group differences in levels of and changes in (level $\times$ time interactions) organisational justice

\begin{tabular}{|c|c|c|c|c|c|c|c|c|c|}
\hline \multirow[b]{3}{*}{$\begin{array}{l}\text { Baseline } \\
\text { characteristic }\end{array}$} & \multirow[b]{3}{*}{$\mathbf{n}$} & \multicolumn{4}{|c|}{ Procedural justice } & \multicolumn{4}{|c|}{ Relational justice } \\
\hline & & \multicolumn{2}{|l|}{ Mean } & \multicolumn{2}{|c|}{ Difference } & \multicolumn{2}{|l|}{ Baseline } & \multicolumn{2}{|l|}{ Mean } \\
\hline & & Baseline & $\begin{array}{l}\text { Follow } \\
\text { up }\end{array}$ & Level & $\begin{array}{l}\text { Level } \\
\times \text { time }\end{array}$ & Baseline & $\begin{array}{l}\text { Follow } \\
\text { up }\end{array}$ & Level & $\begin{array}{l}\text { Level } \\
\times \text { time }\end{array}$ \\
\hline Men & 407 & 2.83 & 2.72 & & & 3.65 & 3.61 & & \\
\hline $\begin{array}{l}\text { Age (years) } \\
\quad<45 \\
\geqslant 45\end{array}$ & $\begin{array}{l}187 \\
220\end{array}$ & $\begin{array}{l}2.70 \\
2.94\end{array}$ & $\begin{array}{l}2.55 \\
2.87\end{array}$ & $<0.001$ & 0.187 & $\begin{array}{l}3.70 \\
3.61\end{array}$ & $\begin{array}{l}3.61 \\
3.60\end{array}$ & 0.557 & 0.329 \\
\hline $\begin{array}{c}\text { Income } 1100 \\
\quad \leqslant 137.9 \\
>137.9\end{array}$ & $\begin{array}{c}0 \text { FIM p } \\
178 \\
198\end{array}$ & $\begin{array}{l}\text { r year) } \\
2.68 \\
2.96\end{array}$ & $\begin{array}{l}2.61 \\
2.81\end{array}$ & 0.003 & 0.240 & $\begin{array}{l}3.56 \\
3.71\end{array}$ & $\begin{array}{l}3.46 \\
3.69\end{array}$ & 0.029 & 0.432 \\
\hline $\begin{array}{l}\text { Medically ce } \\
\text { No } \\
\text { Yes }\end{array}$ & $\begin{array}{c}\text { ertified si } \\
270 \\
104\end{array}$ & $\begin{array}{l}\text { kness abse } \\
2.85 \\
2.70\end{array}$ & $\begin{array}{l}\text { nce } \\
2.74 \\
2.64\end{array}$ & 188 & 0.499 & $\begin{array}{l}3.74 \\
3.46\end{array}$ & $\begin{array}{l}3.69 \\
3.41\end{array}$ & 0.003 & 0.995 \\
\hline $\begin{array}{l}\text { Minor psychi } \\
\text { No } \\
\text { Yes }\end{array}$ & $\begin{array}{c}\text { iatric mc } \\
326 \\
77\end{array}$ & $\begin{array}{l}\text { rbidity } \text { (GH } \\
2.90 \\
2.56\end{array}$ & $\begin{array}{l}\text { Q-12 } \geqslant 4) \\
2.80 \\
2.37\end{array}$ & .001 & 0.295 & $\begin{array}{l}3.70 \\
3.45\end{array}$ & $\begin{array}{l}3.64 \\
3.48\end{array}$ & 0.047 & 0.416 \\
\hline $\begin{array}{l}\text { Poor self rate } \\
\text { No } \\
\text { Yes }\end{array}$ & $\begin{array}{c}\text { ed health } \\
315 \\
90\end{array}$ & $\begin{array}{r}\text { status } \\
2.90 \\
2.57\end{array}$ & $\begin{array}{l}2.76 \\
2.55\end{array}$ & 0.004 & 0.167 & $\begin{array}{l}3.75 \\
3.30\end{array}$ & $\begin{array}{l}3.67 \\
3.37\end{array}$ & $<0.001$ & 0.146 \\
\hline $\begin{array}{l}\text { Women } \\
\text { Age (years) } \\
<45 \\
\geqslant 45\end{array}$ & $\begin{array}{l}3325 \\
1631 \\
1694\end{array}$ & $\begin{array}{l}2.79 \\
2.89\end{array}$ & $\begin{array}{l}2.67 \\
2.79\end{array}$ & $<0.001$ & 0.311 & $\begin{array}{l}3.60 \\
3.65\end{array}$ & $\begin{array}{l}3.55 \\
\\
3.50 \\
3.59\end{array}$ & 0.017 & 0.115 \\
\hline $\begin{array}{c}\text { Income } 1100 \\
\quad \leqslant 123.5 \\
>123.5\end{array}$ & $\begin{array}{l}0 \text { FIM p } \\
1470 \\
1817\end{array}$ & $\begin{array}{l}\text { r year) } \\
2.96 \\
2.74\end{array}$ & $\begin{array}{l}2.84 \\
2.64\end{array}$ & $<0.001$ & 0.271 & $\begin{array}{l}3.65 \\
3.61\end{array}$ & $\begin{array}{l}3.56 \\
3.55\end{array}$ & 0.413 & 0.205 \\
\hline $\begin{array}{l}\text { Medically ce } \\
\text { No } \\
\text { Yes }\end{array}$ & $\begin{array}{l}\text { ertified si } \\
1807 \\
1200\end{array}$ & $\begin{array}{l}\text { ekness ab } \\
2.86 \\
2.81\end{array}$ & $\begin{array}{l}\text { nce } \\
2.72 \\
2.72\end{array}$ & 0.361 & 0.101 & $\begin{array}{l}3.68 \\
3.58\end{array}$ & $\begin{array}{l}3.60 \\
3.48\end{array}$ & $<0.001$ & 0.448 \\
\hline $\begin{array}{l}\text { Minor psychi } \\
\text { No } \\
\text { Yes }\end{array}$ & $\begin{array}{c}\text { iatric mc } \\
2577 \\
700\end{array}$ & $\begin{array}{l}\text { rbidity IGH } \\
2.88 \\
2.69\end{array}$ & $\begin{array}{l}\text { Q-12 } \geqslant 4) \\
2.76 \\
2.62\end{array}$ & $<0.001$ & 0.110 & $\begin{array}{l}3.67 \\
3.46\end{array}$ & $\begin{array}{l}3.59 \\
3.39\end{array}$ & $<0.001$ & 0.881 \\
\hline $\begin{array}{l}\text { Poor self rate } \\
\text { No }\end{array}$ & $\begin{array}{l}\text { ed health } \\
2702\end{array}$ & $\begin{array}{r}\text { status } \\
2.85\end{array}$ & 2.73 & 0.560 & 0.039 & 3.64 & 3.56 & 0.056 & 0.950 \\
\hline Yes & 603 & 2.80 & 2.74 & & & 3.56 & 3.49 & & \\
\hline
\end{tabular}

No sex differences in levels of procedural justice $(p=0.354)$ and relational justice $(p=0.173)$. There was a declining trend in procedural and relational justice $(p<0.001)$. 


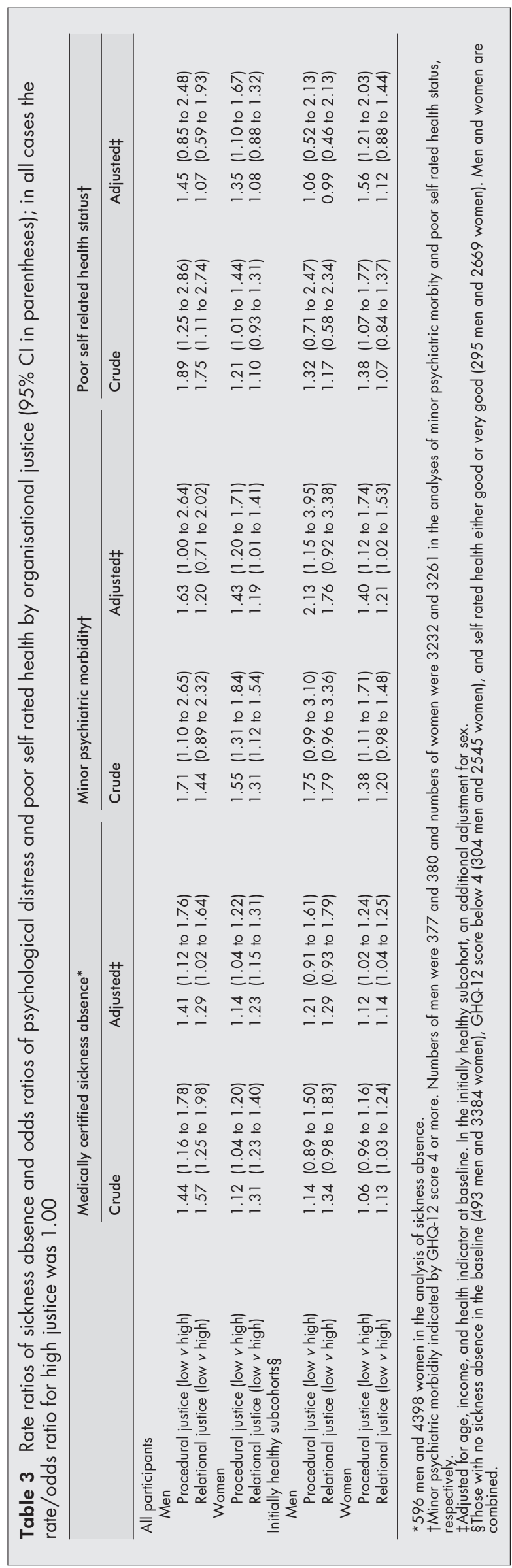

absence (71.1 $v 42.7$ spells per 100 person-years, $\mathrm{p}<0.001$ ) and prevalence of minor psychiatric morbidity (25\% v $21 \%$, $\mathrm{p}=0.012$ ) at baseline than those who kept their jobs. Those lost to follow-up were also younger (40.5 v 44.3 years, $\mathrm{p}<0.001$ ) and had a higher annual income (135276 v 130333 FIM, p < 0.001) but did not differ in terms of sex, procedural and relational justice, and self-rated health status.

Of the 554 men and 4140 women who remained in the service of the hospitals, 3773 (416 men and 3357 women) responded to the follow-up survey, a response rate of $80 \%$. Respondents did not differ from the eligible population in terms of age ( $46.4 v 46.3$ years), annual income (130 $487 v$ 130334 FIM) and sex (88\% v 88\% female). Nurses were slightly over-represented, but proportions of other occupational groups did not differ between respondents and the eligible population $(<1 \%$ tolerance, see table 1$)$.

\section{Levels of organisational justice}

There was a declining trend in procedural and relational justice between the baseline and follow up surveys ( $p<0.001$ ) but no difference was found in these components between men and women. Although levels of organisational justice were lower in those with health problems at baseline, no support was found for the reverse causality hypothesis (table 2).

\section{Effect of organisational justice on health}

Table 3 presents results on the associations between procedural and relational justice, and health by sex. The rate ratios and odds ratios slightly vary between men and women, but analyses reveal that there were no statistically significant interactions between organisational justice components and sex or age on the health outcomes studied.

Procedural justice was linked with all the health outcomes. After adjustment for sex, age, income, and baseline health, low procedural justice, compared to high procedural justice, was associated with a 1.15 times (95\% confidence intervals, CI, 1.08 to 1.23 ) higher risk of sickness absence in the total sample combining men and women. A significant difference was found between income groups $(p=0.050)$. The ratio in sickness absence rates between employees experiencing low versus high procedural justice was 1.25 (95\% CI 1.13 to 1.38 ) in high income employees and 1.07 (95\% CI 0.98 to 1.17) in low income employees. In the total sample, corresponding odds ratios (OR) for minor psychiatric morbidity and poor self rated health were 1.44 (95\% CI 1.22 to 1.70$)$ and 1.37 (95\% CI 1.13 to 1.66 ), respectively, and there were no interactions with income.

Low relational justice was associated with an increased risk of sickness absence (rate ratio $(\mathrm{RR})=1.23,95 \%$ CI 1.15 to $1.31)$ and minor psychiatric morbidity $(\mathrm{OR}=1.19,95 \% \mathrm{CI}$ 1.02 to 1.40$)$, but the association with self rated health status was non-significant $(\mathrm{OR}=1.08,95 \%$ CI 0.89 to 1.31$)$. No interactions between relational justice and income were found.

In relation to adjusted regression models, all significant associations between organisational justice and health among women were replicated in the initially healthy subcohort. Among initially healthy men, adjusted rate ratios and odds ratios for relational justice corresponded to those observed in all men. However, the associations of procedural justice with sickness absence and self rated health status were weaker, and those with minor psychiatric morbidity stronger than the corresponding associations in all men (table 3 ).

\section{Associations with other predictors of health}

Low procedural justice was associated with increased prevalence of smoking in women (OR 1.19,95\% CI 1.01 to 1.40 ) and heavy alcohol consumption in men $(\mathrm{OR}=1.57,95 \% \mathrm{CI} 1.12$ to 2.20 ). Low relational justice was associated with obesity in 
Table 4 Correlations (Pearson's $r$ ) between psychosocial factors at baseline; correlations for men are on the lower diagonal, and correlations for women on the upper diagonal

\begin{tabular}{|c|c|c|c|c|c|c|c|}
\hline & \multicolumn{7}{|c|}{ Psychosocial factor } \\
\hline & 1 & 2 & 3 & 4 & 5 & 6 & 7 \\
\hline 1 Procedural justice & & $0.29 *$ & $0.09 *$ & -0.01 & $-0.21^{*}$ & -0.03 & $-0.11^{*}$ \\
\hline 2 Relational justice & $0.33^{*}$ & & 0.24 * & $0.15^{*}$ & -0.16 * & $0.05^{*}$ & -0.10 * \\
\hline 3 Decision authority & $0.29 *$ & 0.26 * & & $0.45^{*}$ & -0.04 * & $0.12^{*}$ & $-0.03^{*}$ \\
\hline 4 Skill discretion & 0.06 & $0.13^{*}$ & $0.52^{*}$ & & $0.13^{*}$ & $0.16 *$ & -0.04 * \\
\hline 5 Workload & $-0.25^{*}$ & $-0.16^{*}$ & -0.01 & $0.22 *$ & & -0.01 & 0.09 * \\
\hline 6 Social support & $0.08^{*}$ & $0.14^{*}$ & 0.07 & 0.11 * & -0.08 & & $-0.06^{*}$ \\
\hline 7 Hostility & $-0.13^{*}$ & $-0.09 *$ & 0.02 & -0.01 & $0.08^{*}$ & $-0.10^{*}$ & \\
\hline
\end{tabular}

${ }^{*} \mathrm{~A}$ statistically significant correlation is depicted as $\mathrm{p}<0.05$.

women $(\mathrm{OR}=1.30,95 \%$ CI 1.08 to 1.57$)$. All other associations between organisational justice and behavioural and biological factors were non-significant.

The correlation matrix of table 4 shows relations between organisational justice and other psychosocial factors. Low procedural justice was associated with low relational justice, low decision authority, high workload, low social support (only in men), and high hostility. Relational justice was correlated with all psychosocial factors studied. Directions of these associations were similar to those found for procedural justice. Low relational justice was associated with low skill discretion.

Table 5 summarises in two sets of models how adjustment for other health risk factors affected the association between organisational justice and health. Model 1 shows that adjustment for behavioural and biological factors did not alter this association (cf. table 3). Model 2, the fully adjusted model, indicates that all associations between procedural justice and indicators of health remained significant after additional adjustment for other psychosocial factors. In the fully adjusted model, procedural justice was a stronger predictor of sickness absence among high income employees $(\mathrm{RR}=1.17$, 95\% CI 1.05 to 1.31 ) than among low income employees $(\mathrm{RR}=0.95,95 \% \mathrm{CI} 0.85$ to 1.05$)$, replicating the interaction found in previous models with fewer adjustments (cf. table 3). The $p$ value for the interaction between procedural justice and income was 0.013 .

In the fully-adjusted models, relational justice predicted sickness absence but not minor psychiatric morbidity (table 5). No interactions between relational justice, sex, age, and income were found.

The fully adjusted models allow evaluation of independent contributions of components of organisational justice and other psychosocial risk factors. Procedural justice was the strongest predictor of poor self rated health status, and the second strongest predictor of minor psychiatric morbidity; its effect on medically certified sickness absence was equal to those related to components of job control.

\section{DISCUSSION}

This is apparently the first longitudinal study to show that the extent to which employees are treated with justice predicts their health. The association between low organisational justice and increasing health problems was observable across all the health outcomes studied, among men and women representing not only medical professions, but also administrative and maintenance jobs, and in the initially healthy subcohorts. Although not very large, the size of the effect was comparable to those related to established psychosocial determinants of morbidity such as job control, overload, and hostility. No evidence was found to support the reverse causality hypothesis or that the association between organisational justice and health is attributable to relations between other psychosocial factors, behavioural and biological variables, and health.
The health outcomes studied-sickness absence, GHQ caseness, indicating minor psychiatric morbidity, and self rated health status - are not clinically insignificant measures. Sickness absence is a good indicator of health in the working population when health is understood as a combination of social, psychological, and physical functioning. ${ }^{22}$ In this study, all spells of absence had been certified by a doctor. Infections, musculoskeletal disorders, and injuries have been found to account for the majority of such absences. ${ }^{21}$ The General Health Questionnaire is a well established screening instrument for minor psychiatric disorders in general population samples, ${ }^{12}$ and more than 20 published studies have consistently shown that global self rated health is an independent predictor of mortality, despite the inclusion of numerous specific health status indicators and other relevant covariates known to predict mortality. ${ }^{23}$

Low procedural and relational justice equally increased the likelihood of medically certified sickness absence, but for procedural justice there was an interaction with socioeconomic status. Differences in health effects between income groups suggest that procedural justice may have more salient meanings for members of highly ranked occupations close to management than for employees in lower ranking occupations. Minor psychiatric morbidity and self rated health status were more strongly predicted by the procedural than the relational component of justice. This is in line with earlier cross sectional findings, ${ }^{10}$ and suggests that a low justice work environment characterised by unjust organisational policies, practices, and procedures is a greater risk to health than unfair treatment from an immediate supervisor.

Although the possibility of confounding by an unknown factor can never be excluded, a major bias in our study is unlikely. Firstly, both components of organisational justice were only moderately related to other psychosocial factors. Secondly, the contribution of procedural justice largely persisted after control for 14 other psychosocial, behavioural, and biological factors. This analysis is extremely conservative. An observed effect after such adjustments is probably an underestimation of the true effect because risk factors tend to concentrate among the same people and they may represent different stages of the same pathogenic process. Job control, workload, and social support, the main elements in the well established job strain model, refer to an individual's job characteristics or situations in which one may need help. ${ }^{20}$ It is possible that organisational justice captures more basic elements of social structure in which this and other psychosocial models may be operating.

The response rates of our surveys were high but attrition was greater among those employees who had health problems, as indicated by sickness absence rate. Such selection may have caused a healthy worker effect and thus attenuated the association between organisational justice and health. Nurses were the largest occupational group, and they were also slightly over represented in the study sample. Thus, the 


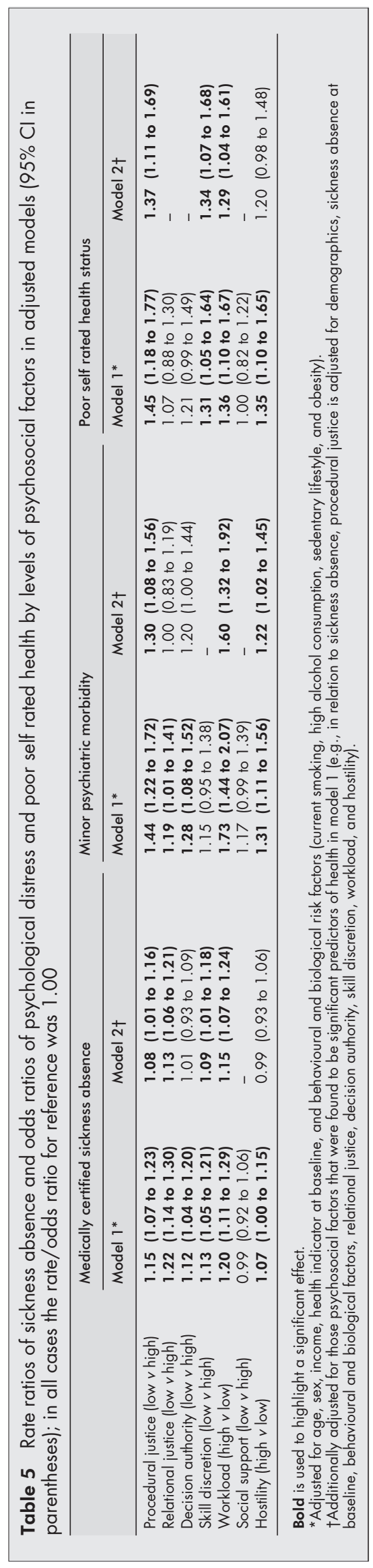

Main messages

- Research on health effects of psychosocial work characteristics has traditionally focused on job control, job demands, and social support.

- Broadening the view to managerial procedures and treatment of individuals in organisations seems now to be important.

- Low organisational justice is an independent risk factor to the health of employees.

- The size of the effect is comparable to those observed for established psychosocial determinants of morbidity, such as low job control, overload, and hostility.

\section{Policy implications}

- Decision making procedures should include input from affected parties, and be consistently applied, unbiased, open, correctable, and ethical.

- A prerequisite for high organisational justice is the respectful and considerate treatment of individuals by their supervisors.

- Attention to decision making procedures and interpersonal treatment will decrease the risk of ill health among employees.

findings reflect to a great extent these people. A more detailed analysis of the role of organisational justice for hospital physicians, who were under represented in the first survey, is planned to be carried out with larger samples. During the study period, there was a slight decline in procedural and relational justice, which is congruent with the general decline in quality of work life in Finland. ${ }^{24}$

We did not find statistically significant sex differences in the associations between components of organisational justice and health. However, further research on this issue is still needed in non-hospital settings and with a greater number of male participants. Hospital occupations are highly gender specific, making it difficult to determine whether sex or occupation is the cause of potential differences.

\section{Conclusions}

All the findings reported here suggest that organisational justice at work may be a crucial and independent aspect of the psychosocial environment influencing morbidity in working populations. The traditional focus on work characteristics, social support, and personality has been an important first step, but broadening the view to managerial procedures and treatment of individuals in organisations seems now to be important. Such a perspective may not only increase our understanding of psychosocial risks, but also suggest new priorities for strategies of promotion of health and wellbeing at workplaces.

\section{ACKNOWLEDGEMENTS}

Funding: the Finnish Work Environment Fund (FWEF) (project 97316) and the Academy of Finland (projects 44968 and 77560) for MK, the FWEF (projects 96052 and 801639) for ME and JV, and the Economic and Social Research Council (L 128251046) for JEF.

Authors' affiliations

M Kivimäki, Department of Psychology, Finnish Institute of Occupational Health, Topeliuksenkatu 41 aA, FIN-00250 Helsinki, Finland $M$ Elovainio, Research and Development Centre for Health and Welfare, PO Box 220, FIN-00591 Helsinki, Finland

J Vahtera, Finnish Institute of Occupational Health, Hämeenkatu 10, FIN-20500 Turku, Finland

J E Ferrie, Department of Epidemiology and Public Health, University College London Medical School, 1-19 Torrington Place, London WCIE 6BT, UK 


\section{REFERENCES}

1 Schnall PL, Landsbergis PA, Baker D. Job strain and cardiovascular disease. Ann Rev Public Health 1994;15:381-411.

2 Bosma H, Marmot MG, Hemingway $\mathrm{H}$, et al. Low job control and risk of coronary heart disease in the Whitehall II (prospective cohort) study. BM 1997;314:558-64

3 Everson SA, Lynch JW, Chesney MA, et al. Interaction of workplace demands and cardiovascular reactivity in progression of carotid atherosclerosis: population based study. BM 1997;314:553-8.

4 Johnson JV, Stewart W, Hall EM, et al. Long-term psychosocial work environment and cardiovascular mortality among Swedish men. Am J Public Health 1996;86:324-31.

5 Hemingway $\mathbf{H}$, Marmot M. Psychosocial factors in the aetiology and prognosis of coronary heart disease: systemic review of prospective cohort studies. BM 1999;318:1460-7.

6 Miller DT. Disrespect and experience of injustice. Ann Rev Psychol 2001;52:527-80

7 Cropanzano R, Byrne ZS, Bobocel DR, et al. Moral virtues, fairness heuristics, social entities, and other denizens of organizational justice. J Voc Behav 2001;58:164-209.

8 Shapiro DL, Brett JM. Comparing three processes underlying judgements of procedural justice: a field study of mediation and arbitration. J Personality Social Psychol 1993:65:1167-77.

9 Richards JC, Hof A, Alvarenga M. Serum lipids and their relationships with hostility and angry affect in men. Health Psychol 2000;19:393-8.

10 Elovainio M, Kivimäki M, Vahtera J. Organizational justice: evidence of a new psychosocial predictor of health. Am J Public Health 2002;92:105-8.

11 Moorman RH. Relationship between organizational justice and organizational citizenship behaviors: do fairness perceptions influence employee citizenship? J Appl Psychol 1991;76:845-55

12 Goldberg D, Williams P. A user's guide to the General Health Questionnaire. Berkshire: NFER-Nelson Publishing Co., 1988

13 Kaprio J, Koskenvuo M, Langinvainio $H$, et al. Genetic influences on use and abuse of alcohol: a study of 5638 adult Finnish twin brothers. Alcohol Clin Exp Res 1987;1 1:349-56

14 Kujala UM, Kaprio J, Sarna S, et al. Relationship of leisure-time physical activity and mortality. JAMA 1998;279:440-4.

15 Karasek R. Job content questionnaire and user's guide. Revision 1.1, 1985

16 Sarason IG, Sarason BR, Shearin EN, et al. A brief measure of social support: practical and theoretical implications. J Soc Pers Relat 1987:4:497-510.

17 Koskenvuo M, Kaprio J, Rose RJ, et al. Hostility as a risk factor for mortality and ischemic heart disease in men. Psychosom Med 1988;50:330-40.

18 Ferrie JE, Shipley M, MArmot MG, et al. An uncertain future: the health effects of threats to employment security in white-collar men and women. Am J Public Health 1998;88: 1030-6.

19 Kivimäki M, Vahtera J, Pentti J, et al. Factors underlying the effect of organisational downsizing on health of employees: longitudinal cohort study. BM 2000;320:971-5.

20 Theorell T, Karasek RA. Current issues relating to psychosocial job strain and cardiovascular disease research. J Occup Health Psychol 1996;1:9-26.

21 Vahtera J, Kivimäki $M$, Pentti J. Effect of organizational downsizing on health of employees. Lancet 1997; 350: 1 124-8.

22 Marmot MG, Feeney A, Shipley M, et al. Sickness absence as a measure of health status and functioning: from the UK Whitehall II study. J Epidemiol Community Health 1995;49:124-30.

23 Idler EL, Benyamini Y. Self-rated health and mortality: a review of twenty-seven community studies. J Health Soc Behav 1997;38:21-37.

24 Piirainen H, Elo A-E, Hirvonen M, et al. Work and health: survey of Finnish workforce (in Finnish). Helsinki: Finnish Institute of Occupational Health, 2000.

\section{COMMENTARY}

The demand control model has been heavily influential in the area of research on occupational stress during the 1990s. ${ }^{1}$ The key element in it is decision latitude for employees-that is, the possibility for employees to influence their own working conditions. The idea behind this is that the work environment may or may not provide opportunity for the employees to have a say in decisions related to their own work. This has mostly been measured by means of self administered questionnaires with general questions about authority over decisions and intellectual discretion. Few attempts have been made to test the significance of other related concepts which could expand the original model. Kivimäki et al have now tested the idea that organisational justice may be a crucial concept of this kind. Accordingly they have tested one index related to procedural justice and another index related to relational justice.
The first one is clearly related to decision authority in the original demand control model, but the four questions deal with procedures used at the work site and the extent to which they create clarity and consistency for the employees around decisions at work. The other one is more close to supervisor support at work since all four questions deal with the supervisor's function and whether he/she is able to deal with the employee in a respectful and fair way. Kivimäki et al have tested the ability of these two indices to predict sickness absence, minor psychiatric morbidity, and self rated health, and they have done so in 416 male and 3357 female hospital employees in Finland from 1998 (baseline) to 2000.

The results of multivariate analyses showed that procedural justice and relational justice were both predictors of poor health, even when the concomitant effects of authority over decisions, skill discretion, workload (closely corresponding to demands in the demand control model), social support, and hostility had been adjusted for. Adjustments had also been done for current smoking, high alcohol consumption, sedentary lifestyle, and obesity. The results indicated that procedural justice was in general more important to health than relational justice, except for medically certified sickness absence for which the reverse was true-relational justice was more important. The odds ratios were rather small, but still potentially important from a public health point of view. The three components of the demand control model, workload, decision authority, and skill discretion, also contributed to predictions of the three health outcomes, but the patterns were different. High work load and low decision authority were particularly important to minor psychiatric morbidity during follow up, whereas low skill discretion was of particular importance to self rated health. Social support at work was not predictive of health, whereas hostility was a predictor of minor psychiatric morbidity. It is important to note that the contributions of these different factors were adjusted for one another. Accordingly, a significant effect of one of them on health could not be explained by the others. It is particularly interesting that hostility was included as an explanatory factor. When associations between a psychosocial variable and an outcome variable has been found it can always be argued that the real explanation may be a personality variable. Certain personality traits could increase the likelihood that participants who complain about many things in life are likely to complain both about work and about health, and hence trivial associations will arise. In addition the new dimensions predicted independently of the old demand control model. Hence procedural justice, in the form it has been proposed by the authors, is not merely a new version of the old demand control model, but something new.

Warnings about lack of generalisability have to be issued. The study has been made in one country and in one group of employees (hospital employees) who represent one kind of public sector workers. The study was made during a post-crisis period in Finland and it is possible, for instance, that procedural fairness may have been considered particularly crucial during this period. There was a female dominance among the participants and therefore we do not know whether the results are applicable to men. Despite all these limitations it is my hope that these methods will be utilised by other researchers. In particular the concept procedural justice may be very useful since it reflects the employees' perception of the effort that the organisation makes in order to create good decision authority for them. The original concept decision authority is more global since the total perception of the possibility to influence decisions may also be influenced by, for instance, work tasks, other employees, and possible patients/customers. Labour and financial markets are of profound importance as well.

How is procedural justice influencing health? Firstly we need to know whether this new concept is related to physiological outcome variables. Future research will certainly 
explore this. A low decision latitude (the combination of intellectual discretion and decision authority) in combination with high psychological demands (job strain) has been shown to be related to blood pressure regulation. ${ }^{2}$ It could be that procedural justice is related to health outcomes in similar ways - through physiological stress mechanisms. More indirect ways are also possible, for instance through effects on coping mechanisms. In a study which we performed some years ago within the framework of the epidemiological study WOLF, we explored how employees cope with situations at work characterised as "being treated in an unfair way" by either colleagues or by superiors. ${ }^{3}$ The findings indicated that decision latitude was of marked significance to ways of coping with this situation. When decision latitude was small, employees were much more likely to cope in a less open and more covert way. We could put it in a more blunt way: employees who found that they had no say and that it did not matter what opinions they had were less likely to tell the person who had treated them in this unfair way about their feelings of being humiliated. It could be that the associations with procedural justice and relational justice would be even stronger. Particularly among middle aged men, a high degree of covert coping was related to high blood pressure in the WOLF study.

It is possible that procedural injustice becomes internalised. After some time, workers exposed to an organisation that does not take the opinions of the workers into account will stop discussing problems (and possibilities!) with their leaders. In the long run this will lead not only to health problems for the employees but also to lost creativity in the organisation. The democracy fundamentals are at stake in this research — which seems to be of vital importance. In the future we shall need research on other occupational groups and in other countries, on men as well as on women, and we need to know about the significance of organisational justice, not only to broad health indicators but also to physiological outcomes, as well as to creativity and long term survival of people and organisations.

This kind of research could give us clues to the broader health inequity question: Why is it that lower socioeconomic strata of the population have higher morbidity and mortality? Organisational injustice may contribute to this.

T Theorell

National Institute for Psychosocial Factors and Health, Box 230, Stockholm S-171 77, Sweden; tores.theorell@ipm.ki.se

\section{REFERENCES}

1 Karasek RA, Theorell T. Healthy work. New York: Basic Books, 1990.

2 Schnall P, Belkic K, Landbergis P, Baker D, eds. Occupational medicine. The workplace and cardiovascular disease. Philadelphia, PA: Hanley \& Belfus, Inc., 2000:24-46.

3 Theorell T, Alfredsson L, Westerholm P, et al. Coping with unfair treatment at work - what is the relationship between coping and hypertension in middle-aged men and women. Psychother Psychosom 2000;69:86-94

\section{$\mathrm{ECHO}$}

\section{First aiders need to raise their game}

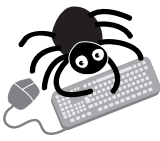

Please visit the Occupational and

Environmental Medicine website [www. occenvmed.com for link to this full article.
- irst aiders to youth football league clubs must raise their knowledge and standards to provide proper - safeguards for players. Results disclosed by a preliminary survey prompt its author to call for the Football Association (FA)-UK football's governing body-and the Health and Safety Executive to list first aid equipment, facilities, and qualified staff for clubs to access.

Thirty four percent (86/250) of first aiders responded to the questionnaire. Almost three quarters of them had been involved in football for up to 10 years, and half with the $8-11$ year age group, but $60 \%$ had no current first aid qualification. Their responses to a range of hypothetical injury scenarios was patchy_and holding a current qualification did not guarantee a correct answer. Three quarters did not judge themselves competent to cope with a diabetic attack, and around half an asthma attack, epileptic fit, or a fracture. Respondents judged the equipment available at games and training sessions as satisfactory, even though various items that should be standard were lacking. About $40 \%$ kept health records on the players but only $19 \%$ kept injury reports. Written parental consent to emergency treatment was held by only $30 \%$.

The questionnaire, with a letter of explanation, was sent to clubs in two youth football leagues-in the midlands and northern England - to be forwarded to the club's first aider.

Neither the FA, nor Sports Coach UK, in its code of ethics and conduct, requires a sports first aid qualification. Nevertheless, UK law places liability with both the first aider and the club.

A British Journal of Sports Medicine 2002;36:295-300 